\title{
Hemoglobin A1C but not Glycated Albumin Overestimates Glycemic Control due to Iron Deficiency in Pregnant Women with Diabetes
}

\author{
Tatsumi Moriya ${ }^{1}$, Madoka Matsubara ${ }^{1}$ and Masafumi Koga ${ }^{2 \star}$
}

${ }^{1}$ Health Care Center, Kitasato University, Kanagawa, Japan

${ }^{2}$ Department of Internal Medicine, Kawanishi City Hospital, Hyogo, Japan

\begin{abstract}
Background: Pregnant women are frequently complicated with iron deficiency. Because Hemoglobin A1c (HbA1c) shows an apparently high value in patients with iron-deficiency, $\mathrm{HbA1c}$ was reported to be elevated due to iron deficiency in pregnant women with or without diabetes. In the present study, we investigated whether $\mathrm{HbA} 1 \mathrm{c}$ or Glycated Albumin (GA) accurately reflects glycemic control state estimated from the Mean Blood Glucose (MBG) obtained by Continuous Glucose Monitoring (CGM) in pregnant women with diabetes.
\end{abstract}

Methods: We studied 20 pregnant women with diabetes whose glycemic control was stable and CGM was performed to determine MBG. The estimated $\mathrm{HbA} 1 \mathrm{c}$ and GA were calculated from the MBG, and the measured values were compared with the estimated values. Correlations between Mean Corpuscular Hemoglobin ( $\mathrm{MCH})$, an index of iron-deficiency, and continuous variables were examined.

Results: HbA1c was not significantly correlated with GA. The measured GA was not significantly different from the estimated $\mathrm{GA}(16.0 \pm 2.7 \%$ vs. $16.0 \pm 1.8 \%, \mathrm{P}=0.982)$. On the other hand, the measured $\mathrm{HbA} 1 \mathrm{c}$ was significantly higher than the estimated $\mathrm{HbA} 1 \mathrm{c}[6.4 \pm 0.9 \%(46.3 \pm 10.3 \mathrm{mmol} / \mathrm{mol})$ vs. $5.6 \pm 0.5 \%(38.2 \pm 5.4 \mathrm{mmol} / \mathrm{mol}), P<0.001]$ The measured $\mathrm{HbA1c}(\mathrm{R}=-0.598, \mathrm{P}=0.005)$ and the measured $\mathrm{HbA} 1 \mathrm{c}$ estimated $\mathrm{HbA} 1 \mathrm{c}$ ratio $(\mathrm{R}=-0.566, \mathrm{P}=0.009)$ showed significant inverse correlations with $\mathrm{MCH}$.

Conclusions: HbA1c overestimates glycemic control due to iron deficiency in pregnant women with diabetes, whereas GA accurately reflected their glycemic control. Therefore, GA is a better index of glycemic control than $\mathrm{HbA1c}$ in pregnant women with diabetes.

Keywords: Glycated albumin; Hba1c; Pregnancy; Iron deficiency; Glycemic control

Abbreviations: HbA1c: Hemoglobin A1c; GA: Glycated Albumin; MBG: Mean Blood Glucose; CGM: Continuous Glucose Monitoring; MCH: Mean Corpuscular Hemoglobin

\section{Introduction}

In pregnant women with diabetes mellitus and women with gestational diabetes, intensive glycemic control during pregnancy is necessary in order to lower the risk of intrauterine fetal death, fetal growth disorders and maternal complications $[1,2]$. The extent of nonenzymatic glycation of proteins increases in patients with diabetes. Of these glycated proteins, hemoglobin $\mathrm{Alc}(\mathrm{HbA1c})$ is widely used as the current standard marker for monitoring chronic glycemic control $[3,4]$, and represents an important target for treatment of patients with diabetes [5].

$\mathrm{HbAlc}$ measurements are known to be profoundly influenced by erythrocytes turnover, in addition to plasma glucose levels $[6,7]$. Blood dilution-related anemia is known to be frequently observed in pregnancy. Iron-deficiency anemia is also often observed, caused by the increased demands for iron in pregnancy [8]. HbAlc levels have been shown to be higher in relation to glycemia in patients with iron deficiency anemia [9-11]. We have shown that HbAlc, but not Glycated Albumin (GA), is elevated due to iron deficiency in pregnant women with or without diabetes $[12,13]$.

It has been shown that continuous glucose monitoring (CGM) is useful for evaluating glycemic control during pregnancy [14]. In the present study, we determined the mean blood glucose (MBG) by conducting CGM in pregnant women with diabetes to examine whether $\mathrm{HbAlc}$ and GA show a close correlation with MBG or not.

\section{Methods}

\section{Study patients}

Twenty pregnant women with diabetes ( 7 patients with type 1 diabetes mellitus and 13 patients with type 2 diabetes mellitus) whose glycemic control was stabilized by treatment at the Department of Endocrinology, Diabetes and Metabolism in Kitasato University Hospital from March 2007 to July 2011 were included (Table 1). Patients with more than a $0.5 \%$ change in $\mathrm{HbAlc}$ in the 2 -month period preceding the CGM and patients complicated with hepatic diseases, renal diseases or thyroid diseases were excluded. Pregnant women who used the iron supplement or received the iron preparation were also excluded.

The reported investigations were carried out in accordance with the principles of the Declaration of Helsinki as revised in 2000. The institutional review board approved this study, and all patients provided written informed consent.

*Corresponding author: Masafumi Koga, Department of Internal Medicine, Kawanish City Hospital, 5-21-1 Higashi-Uneno, Kawanishi, Hyogo 666-0195, Japan, Tel: +81-72 794-2321; Fax: +81-72-794-6321; E-mail: m-koga@kawanishi-city-hospital.com

Received July 26, 2014; Accepted September 27, 2014; Published October 06 2014

Citation: Moriya T, Matsubara M, Koga M (2014) Hemoglobin A1C but not Glycated Albumin Overestimates Glycemic Control due to Iron Deficiency in Pregnant Women with Diabetes. J Diabetes Metab 5: 445 doi:10.4172/2155-6156.1000445

Copyright: @ 2014 Moriya T, et al. This is an open-access article distributed under the terms of the Creative Commons Attribution License, which permits unrestricted use, distribution, and reproduction in any medium, provided the original author and source are credited. 


\begin{tabular}{|l|c|}
\hline$n$ & 20 \\
\hline Type 1 diabetes/type 2 diabetes & $7 / 13$ \\
\hline Age (years) & $33.6 \pm 3.7$ \\
\hline Body mass index $\left(\mathrm{kg} / \mathrm{m}^{2}\right)$ & $26.2 \pm 5.2$ \\
\hline Diabetes duration (years) & $4.2 \pm 3.4$ \\
\hline Gestational age (weeks) & $19.3 \pm 8.6$ \\
\hline Diabetes therapy (diet/insulin) & $3 / 17$ \\
\hline MBG $(\mathrm{mg} / \mathrm{dl})$ & $110 \pm 14$ \\
\hline $\mathrm{HbA1c}(\%)$ & $6.4 \pm 0.9$ \\
\hline $\mathrm{HbA1c}(\mathrm{mmol} / \mathrm{mol})$ & $46.3 \pm 10.3$ \\
\hline $\mathrm{GA}(\%)$ & $16.0 \pm 2.7$ \\
\hline $\mathrm{RBC}\left(\mathrm{x} 10^{6} / \mu \mathrm{l}\right)$ & $4.26 \pm 0.43$ \\
\hline $\mathrm{Hb}(\mathrm{g} / \mathrm{dl})$ & $12.4 \pm 1.0$ \\
\hline $\mathrm{Ht}(\%)$ & $36.8 \pm 2.8$ \\
\hline $\mathrm{MCH}(\mathrm{pg})$ & $29.2 \pm 2.3$ \\
\hline
\end{tabular}

MBG: Mean Blood Glucose; Hba1c: Hemoglobin A1c; GA: Glycated Albumin RBC: Red Blood Cell; Hb: Hemoglobin; Ht: Hematocrit; MCH: Mean Corpuscular Hemoglobin

Table 1: Clinical characteristics of the study patients.

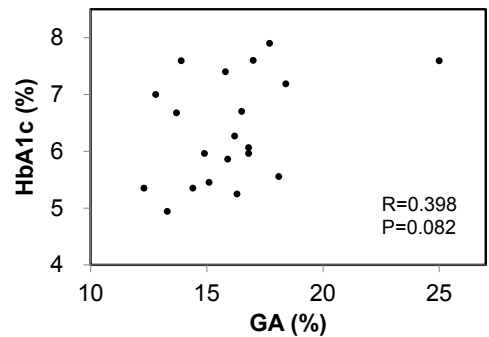

Figure 1: Correlation between $\mathrm{GA}$ and $\mathrm{HbA} 1 \mathrm{c}$ in 20 pregnant women with diabetes.

\section{Measurements}

Blood samples were taken at overnight fasting in the early morning and were measured immediately. $\mathrm{HbAlc}$ was measured by High Performance Liquid Chromatography (HPLC). HbAlc as a Japan Diabetes Society (JDS) value (\%) was converted to a National Glycohemoglobin Standardization Program (NGSP) value or an International Federation of Clinical Chemistry (IFCC) value (\%) in accordance with the official equation [15]. GA was determined by enzymatic methods using albumin-specific protease, ketoamine oxidase and albumin assay reagent (Lucica GA-L; Asahi Kasei Pharma, Tokyo, Japan) [16]. Blood cell counts, hematocrit, hemoglobin, and mean corpuscular hemoglobin $(\mathrm{MCH})$ were measured by an automated hematology system. Inter-assay coefficient variations (CVs) of HbAlc and GA were $0.49 \%$ and $1.35 \%$, respectively.

CGM $\left(\right.$ CGMS $^{\circledR}$ System Gold manufactured by Medtronic MiniMed) was performed for about 72 hours, and the data of two days were averaged using the data collected for 48 hours on Days 2 and 3 after wearing [17]. Calibration during wearing was performed four times or more a day using MediSafe Mini ${ }^{\circledR}$ (TERUMO Corporation, Tokyo, Japan). The estimated HbAlc values were calculated using MBG obtained by CGM according to the following conversion formula established by Nathan et al. [18].

\section{Estimated HbAlc $(\%)=[\mathrm{MBG}(\mathrm{mg} / \mathrm{dl})+46.7] / 28.7$}

Since the GA/HbAlc ratios in patients with type 1 and type 2 diabetes mellitus were 3.1 and 2.7, respectively [19], the estimated GA was determined by multiplying the estimated HbAlc by 3.1 and 2.7 for patients with type 1 and type 2 diabetes mellitus, respectively.

\section{Statistical analyses}

The data were expressed as mean \pm SD. Paired Student's $t$ tests were used to estimate the level of significance of differences between measured values and estimated values. To analyze the effects of explanatory variables, single linear univariate regression analyses were performed. The StatView computer program (version 5.0 for Windows; Abacus Concepts, Berkeley, CA) was used for all statistical analyses. The level of statistical significance was established as less than $5 \%$.

\section{Results}

In 20 pregnant women with diabetes, the age was $33.6 \pm 3.7$ years old, the body mass index was $26.2 \pm 5.2 \mathrm{~kg} / \mathrm{m}^{2}$, the diabetes duration was $4.2 \pm 3.4$ years, and the gestational period was $19.3 \pm 8.6$ weeks (Table 1). Three patients with type 2 diabetes mellitus underwent diet therapy, and the other patients underwent insulin therapy. The MBG obtained by CGM, HbAlc and GA were $110 \pm 14 \mathrm{mg} / \mathrm{dl}, 6.4 \pm 0.9 \%$ $(46.3 \pm 10.3 \mathrm{mmol} / \mathrm{mol})$ and $16.0 \pm 2.7 \%$, respectively. RBC, $\mathrm{Hb}, \mathrm{Ht}$ and $\mathrm{MCH}$ were $4.26 \pm 0.43 \times 106 / \mu \mathrm{l}, 12.4 \pm 1.0 \mathrm{~g} / \mathrm{dl}, 36.8 \pm 2.8 \%$ and $29.2 \pm$ $2.3 \mathrm{pg}$, respectively.,

$\mathrm{HbA} 1 \mathrm{c}$ was not significantly correlated with $\mathrm{GA}(\mathrm{R}=0.398, \mathrm{P}=0.082)$ (Figure 1). The measured GA showed a significant correlation with the estimated GA $(\mathrm{R}=0.707, \mathrm{P}<0.001, \mathrm{y}=1.03 \mathrm{x}-0.53)$, and there was no significant difference between the measured GA and the estimated GA $(16.0 \pm 2.7 \%$ vs. $16.0 \pm 1.8 \%, \mathrm{P}=0.982)$ (Figure $2 \mathrm{~A})$. The regression line between the measured GA and the estimated GA was almost consistent with the straight line of $y=x$. On the other hand, the measured HbAlc showed no significant correlation with the estimated HbAlc (R= $0.422, \mathrm{p}=0.064$ ), and the measured $\mathrm{HbAlc}$ was significantly higher than the estimated $\mathrm{HbAlc}[6.4 \pm 0.9 \%(46.3 \pm 10.3 \mathrm{mmol} / \mathrm{mol})$ vs. 5.6 $\pm 0.5 \%(38.2 \pm 5.4 \mathrm{mmol} / \mathrm{mol}), \mathrm{P}<0.001]$ (Figure 2B). The regression line between the measured $\mathrm{HbAlc}$ and the estimated $\mathrm{HbAlc}$ shifted upwards compared with the straight line of $\mathrm{y}=\mathrm{x}$.

$\mathrm{MCH}$, an index of the iron deficiency, showed no significant correlation with MBG $(\mathrm{R}=-0.136, \mathrm{P}=0.568)$ and $\mathrm{GA}(\mathrm{R}=-0.289$, $\mathrm{P}=0.217$ ), whereas $\mathrm{MCH}$ showed a significant inverse correlation with HbAlc $(\mathrm{R}=-0.598, \mathrm{P}=0.005)$ (Figure 3$). \mathrm{MCH}$ showed no significant

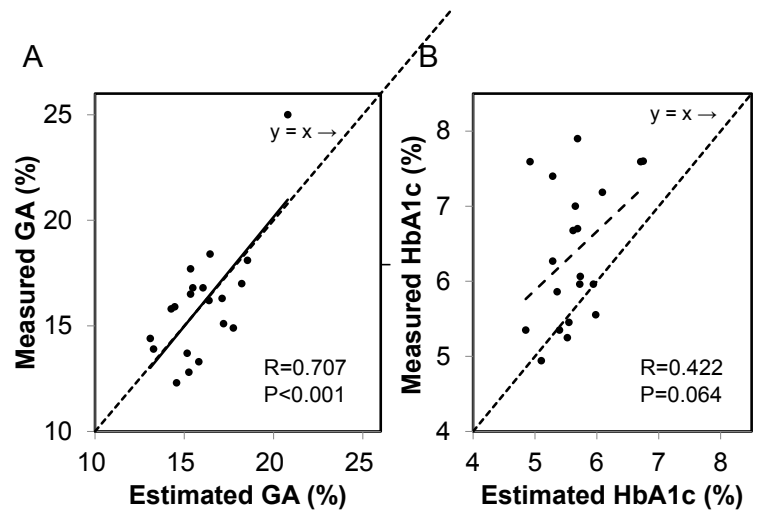

Figure 2: Correlation between the measured values and the estimated values for $\mathrm{GA}(\mathrm{A})$ and $\mathrm{HbA} 1 \mathrm{c}(\mathrm{B})$ in 20 pregnant women with diabetes The line of $\mathrm{y}=$ $x$ is shown with a dotted line and the regression lines between the measured values and the estimated values are shown in a straight line $(A)$ and a dashed line (B). 
A

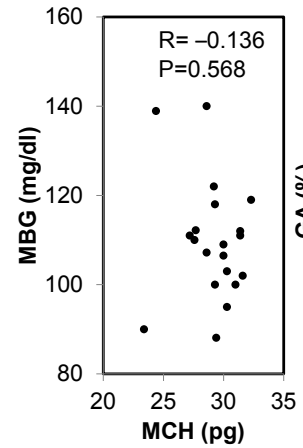

B

C

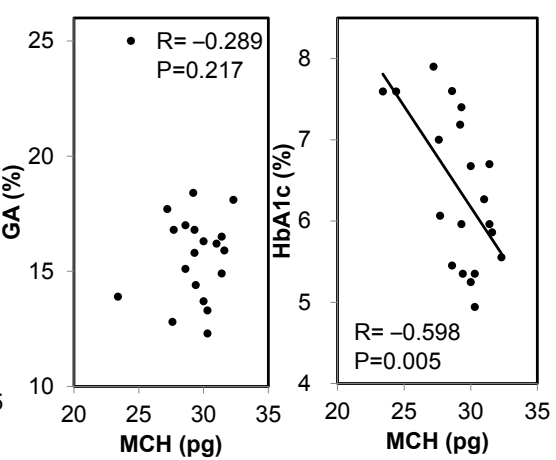

Figure 3: Correlation between mean corpuscular hemoglobin $(\mathrm{MCH})$ and mean blood glucose (MBG) (A), GA (B) and HbA1c (C) in 20 pregnant women complicated with diabetes.
A

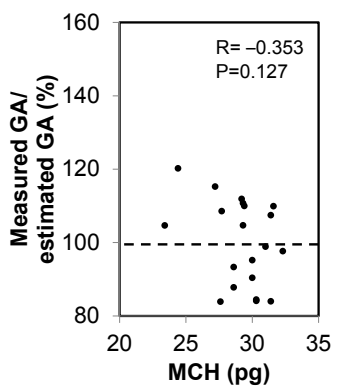

B

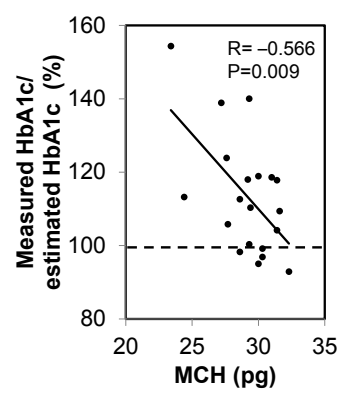

Figure 4: Correlation between mean corpuscular hemoglobin $(\mathrm{MCH})$ and the measured GA/estimated GA ratio $(A)$ and the measured HbA1c/estimated $\mathrm{HbA} 1 \mathrm{c}$ ratio $(\mathrm{B})$ in 20 pregnant women with diabetes. The measured $\mathrm{GA}$ estimated $\mathrm{GA}$ ratio and the measured $\mathrm{HbA} 1 \mathrm{c}$ /estimated $\mathrm{HbA} 1 \mathrm{c}$ ratio of $100 \%$ is shown with a dashed line.

correlation with the measured $\mathrm{GA}$ /estimated $\mathrm{GA}$ ratio $(\mathrm{R}=-0.353$, $\mathrm{P}=0.127$ ), whereas $\mathrm{MCH}$ showed a significant inverse correlation with the measured $\mathrm{HbAlc}$ /estimated HbAlc ratio $(\mathrm{R}=-0.566, \mathrm{P}=0.009)$ (Figure 4). The $\mathrm{MCH}$ also showed a significant inverse correlation with the measured/estimated $\mathrm{HbA} 1 \mathrm{c}$ ratio $(\mathrm{R}=-0.664, \mathrm{P}=0.013)$, but not the measured GA/estimated GA ratio $(\mathrm{R}=-0.047, \mathrm{P}=0.890)$ in the pregnant women with type 2 diabetes mellitus. On the other hand, the $\mathrm{MCH}$ showed no significant correlations with the both ratios in the pregnant women with type 1 diabetes mellitus (data not shown).

\section{Discussion}

In the present study, HbAlc overestimates glycemic control due to iron deficiency in pregnant women with diabetes, whereas GA accurately reflected their glycemic control. MBG as well as GA showed no significant correlation with $\mathrm{MCH}$, but $\mathrm{HbAlc}$ showed a significant inverse correlation with $\mathrm{MCH}$. This result was the similar phenomenon in pregnant women without diabetes reported previously [12]. It is known that iron deficiency itself including iron deficiency anemia does not influence glycemic control but makes HbAlc apparently high [911,20 ]. The findings obtained in the present study were compatible with these previous results. It is considered that the measured $\mathrm{HbAlc}$ showed no significant correlation with the measured GA or the estimated $\mathrm{HbAlc}$ because it is elevated by iron deficiency. As a result, $\mathrm{HbAlc}$ may not accurately reflect glycemic control in pregnant women with diabetes.
If GA or HbA1c accurately reflects glycemic control, the measured value/estimated value ratio should become $100 \%$. For GA, this ratio was distributed between $80 \%$ and $120 \%$. On the other hand, the measured $\mathrm{HbAlc}$ /estimated $\mathrm{HbA} 1 \mathrm{c}$ ratio showed markedly high values of $140 \%$ to $160 \%$ in some patients (Figure 4). Since this ratio showed a significant inverse correlation with $\mathrm{MCH}$, the stronger the degree of iron deficiency, the larger the difference between HbAlc levels and glycemic control state. On the other hand, hemoglobin showed no significant correlation with $\mathrm{HbAlc}$ or the measured $\mathrm{HbAlc}$ /estimated $\mathrm{HbA1c}$ ratio (data not shown). This result suggests that hemoglobin does not necessarily reflect iron deficiency because hemoglobin during pregnancy is also influenced by blood dilution-related anemia.

It is known that hypoglycemia induces perinatal complications together with hyperglycemia [20]. HbAlc in patients with iron deficiency shows apparently high values, so if treatment for diabetes is enforced based on $\mathrm{HbAlc}$ levels during pregnancy, it induces overtreatment for diabetes and the risk of hypoglycemia, and hence the frequency of perinatal complications may increase. It was reported that, in pregnant women with diabetes and patients with gestational diabetes, the frequency of perinatal complications in patients with high GA value was significantly higher than in those with low GA value, but there was no significant difference between patients with high $\mathrm{HbAlc}$ value and those with low HbAlc value [21]. This result might be explained by that hypoglycemia was induced when overtreatment for diabetes was applied in patients apparently showing high HbAlc.

HbA1c did not reflect glycemic control due to iron deficiency, whereas GA accurately reflected glycemic control because it is not influenced by iron deficiency state $[12,13,22]$. GA is known to reflect intermediate-term glycemic control in comparison with HbA1c $[23,24]$. Since it is necessary to improve glycemic control in a short time during pregnancy, the utility of GA as an index of glycemic control during pregnancy has been proposed [22]. In addition, GA reflects glycemic control more accurately than HbAlc during pregnancy, and so it is considered desirable to use GA as an index of glycemic control during pregnancy instead of $\mathrm{HbAlc}$.

The present study has several limitations. First, there were small number of patients; it is necessary to verify the present finding using large number of pregnant women with diabetes in the future. Second, the $\mathrm{MCH}$ showed no significant correlation with the measured value/ estimated value ratios of $\mathrm{HbAlc}$ and GA in pregnant women with type 1 diabetes mellitus. Therefore, it is necessary to verify the present findings using large number of pregnant women with type 1 diabetes. Third, since this was a retrospective study, the gestational period was not constant when CGM was performed; it is necessary to conduct a prospective study in a certain gestational period. Forth, it is considered that $\mathrm{HbAlc}$ and GA reflect glycemic control in the past 1 or 2 months and that in the past 2 weeks, respectively; simultaneous determination of these values with CGM is another issue. Fifth, the present study could not examine the relationship between perinatal complications and the indices of glycemic control; it is necessary to perform CGM at a certain time and to examine which of MBG, HbAlc or GA at that time is related to perinatal complications. It is also necessary to examine the relationship between perinatal complications and the variation of blood glucose obtained with CGM including Standard Deviation (SD) or Mean Amplitude of Glycemic Excursions (MAGE).

In conclusion, $\mathrm{HbAlc}$ overestimates glycemic control due to iron deficiency during pregnancy. On the other hand, GA accurately reflected glycemic control during pregnancy because it is not influenced by iron deficiency. In order to reduce perinatal complications, it is important to 
Citation: Moriya T, Matsubara M, Koga M (2014) Hemoglobin A1C but not Glycated Albumin Overestimates Glycemic Control due to Iron Deficiency in Pregnant Women with Diabetes. J Diabetes Metab 5: 445 doi:10.4172/2155-6156.1000445

achieve good glycemic control using GA as an index of glycemic control instead of $\mathrm{HbAlc}$ in pregnant women with diabetes.

\section{References}

1. Evers IM, de Valk HW, Mol BW, ter Braak EW, Visser GH (2002) Macrosomia despite good glycaemic control in Type I diabetic pregnancy; results of a nationwide study in The Netherlands. Diabetologia 45: 1484-1489.

2. Lauenborg J, Mathiesen E, Ovesen P, Westergaard JG, Ekbom P, et al. (2003) Audit on stillbirths in women with pregestational type 1 diabetes. Diabetes Care 26: $1385-1389$

3. Koenig RJ, Peterson CM, Jones RL, Saudek C, Lehrman M, et al. (1976) Correlation of glucose regulation and hemoglobin Alc in diabetes mellitus. $\mathrm{N}$ Engl J Med 295: 417-420.

4. Bunn HF, Gabbay KH, Gallop PM (1978) The glycosylation of hemoglobin: relevance to diabetes mellitus. Science 200: 21-27.

5. American Diabetes Association (2013) Standards of medical care in diabetes-2013. Diabetes Care 36: S11-S66.

6. Fitzgibbons JF, Koler RD, Jones RT (1976) Red cell age-related changes of hemoglobins Ala+b and Alc in normal and diabetic subjects. J Clin Invest 58 820-824

7. Panzer S, Kronik G, Lechner K, Bettelheim P, Neumann E, et al. (1982) Glycosylated hemoglobins (GHb): an index of red cell survival. Blood 59: 13481350.

8. Scholl TO (2005) Iron status during pregnancy: setting the stage for mother and infant. Am J Clin Nutr 81: 1218S-1222S.

9. Brooks AP, Metcalfe J, Day JL, Edwards MS (1980) Iron deficiency and glycosylated haemoglobin A. Lancet 2: 141.

10. Tarim O, Kucukerdogan A, Gunay U, Eralp O, Ercan I (1999) Effects of iron deficiency anemia on hemoglobin A1c in type 1 diabetes mellitus. Pediatr In 41: 357-362.

11. Coban E, Ozdogan M, Timuragaoglu A (2004) Effect of iron deficiency anemia on the levels of hemoglobin A1c in nondiabetic patients. Acta Haematol 112: 126-128.

12. Hashimoto K, Noguchi S, Morimoto Y, Hamada S, Wasada K, et al. (2008) A1C but not serum glycated albumin is elevated in late pregnancy owing to iron deficiency. Diabetes Care 31: 1945-1948.

13. Hashimoto K, Osugi T, Noguchi S, Morimoto Y, Wasada K, et al. (2010) A1C but not serum glycated albumin is elevated because of iron deficiency in late pregnancy in diabetic women. Diabetes Care 33: 509-511.

14. Sung JF, Taslimi MM, Faig JC (2012) Continuous glucose monitoring in pregnancy: new frontiers in clinical applications and research. J Diabetes Sci Technol 6: 1478-1485.

15. Committee on the Standardization of Diabetes Mellitus-Related Laboratory Testing of Japan Diabetes Society (2012) International clinical harmonization of glycated hemoglobin in Japan: From Japan Diabetes Society to Nationa Glycohemoglobin Standardization Program values. Diabetol Int 3: 8-10.

16. Kouzuma T, Usami T, Yamakoshi M, Takahashi M, Imamura S (2002) An enzymatic method for the measurement of glycated albumin in biological samples. Clin Chim Acta 324: 61-71.

17. Yoshino S, Hayashi A, Kishihara E, Ogawa A, Ichikawa R, et al. (2013) The time interval from meal to peak postprandial glucose levels measured by continuous glucose monitoring in pregnant women with diabetes mellitus. J Japan Diab Soc 56: 646-652. (in Japanese)

18. Nathan DM, Kuenen J, Borg R, Zheng H, Schoenfeld D, et al. (2008) Translating the $\mathrm{A} 1 \mathrm{C}$ assay into estimated average glucose values. Diabetes Care 31: 14731478 .

19. Hirata T, Saisho Y, Morimoto J, Kasayama S, Koga M, et al. (2013) The ratio of glycated albumin to $\mathrm{HbA} 1 \mathrm{c}$ is correlated with diabetes duration according to decreases in insulin secretion in patients with autoimmune type 1 diabetes and type 2 diabetes. J Genet Syndr Gene Ther 4: 168.

20. Langer O, Levy J, Brustman L, Anyaegbunam A, Merkatz R, et al. (1989) Glycemic control in gestational diabetes mellitus--how tight is tight enough: small for gestational age versus large for gestational age? Am J Obstet Gynecol 161: $646-653$

21. Shimizu Y, Hiramatsu Y, Omori M, Nakabayashi M (2010) Glycated albumin reflects maternal and perinatal outcome in a multicenter study in Japan. Diabetes Preg 10: 27-31. (in Japanese)

22. Koga M (2014) Glycated albumin; clinical usefulness. Clin Chim Acta 433: 96 104

23. Tahara Y, Shima K (1995) Kinetics of HbA1c, glycated albumin, and fructosamine and analysis of their weight functions against preceding plasma glucose level. Diabetes Care 18: 440-447.

24. Takahashi S, Uchino H, Shimizu T, Kanazawa A, Tamura $\mathrm{Y}$, et al. (2007) Comparison of glycated albumin (GA) and glycated hemoglobin (HbA1c) in type 2 diabetic patients: usefulness of GA for evaluation of short-term changes in glycemic control. Endocr J 54: 139-144. 